\title{
International Social Economy Organizations
}

\author{
Ignacio Bretos \\ Department of Business Organization and Management \\ University of Zaragoza \\ Anjel Errasti \\ GEZKI Institute of Cooperative Law and Social Economy \\ University of the Basque Country \\ Aurélie Soetens \\ Center for Social Economy \\ University of Liège
}

\begin{abstract}
AUTHORS' PRE-PUBLICATION VERSION. CITE AS:
Bretos, I., Errasti, A., \& Soetens, A. (2021). 'International Social Economy

Organizations'. In: B. Gidron \& A. Domaradzka (Eds.), The New Social and Impact

Economy: An International Perspective (pp. 245-268). Cham, Switzerland: Springer

International Publishing. [ISBN: 978-3-030-68294-1]
\end{abstract}

\begin{abstract}
What strategies do social economy organizations (SEOs) deploy to expand their operations across borders and how scaling social impact is related to each strategy? What are the challenges for international SEOs in preserving and extending their socially oriented practices and values? What approaches can international SEOs adopt to maintain a sustainable balance between social and economic performance? Do they embody a genuine alternative in the international business arena to corporate managerialism and conventional multinationals? This chapter aims to shed light on these questions which are critical to better understand the nature and evolution of the New Social Economy. The discussions are illustrated with examples of high-profile SEOs that are operating successfully on a global scale while engaging in communitarian purposes, social values, and cooperative practices.
\end{abstract}

Keywords: cooperatives; organizational growth; scaling; social economy; social enterprise; social impact. 


\section{Introduction}

Social economy organizations (SEOs) are commonly portrayed in the scholarly literature and public imagination as small sized enterprises that tend to carry out their economic activity exclusively within the local context (Amin, Cameron \& Hudson 2002). What is more, SEOs are seen as antagonistic organizations to conventional multinational corporations (Burke 2010), and serve as buffers against the economic, social and ecological imbalances and issues generated by transnational capitalism and its hypermobility (Imbroscio, Williamson \& Alperovitz 2003). This is due to the fact that SEOs are 'place-based enterprises' (Shrivastava \& Kennelly 2013): they tend to be established as locally owned and democratically controlled enterprises that serve as a vehicle for their members to meet the economic, social, environmental and/or cultural needs of their surrounding community (Peredo \& Chrisman 2006). Small size and local scale of SEOs are argued to be crucial for these organizations to preserve local ownership structures and democratic decision making mechanisms, create sustainable jobs, promote social cohesion and social capital, and strengthen community resilience (Lukkarinen 2005; Sonnino \& Griggs-Trevarthen 2013).

While SEOs have been traditionally seen to be reluctant to grow and expand operations beyond national borders (Rothschild \& Whitt 1986; Smith, Gonin \& Besharov 2013), this has significantly changed in the last few decades. A key trend in the Social Economy sector at a global level lies in the growing adoption of internationalization strategies by SEOs (Bretos \& Marcuello 2017), often through partnerships with public organizations and business corporations (McMurtry \& Reed 2009). The main drivers of international expansion in the Social Economy sector are the growing pressures faced by many SEOs to internationalize if they are to maintain their competitive position in increasingly globalized and dynamic markets (Bretos, Errasti \& Marcuello 2020), and the growing demand to scale their social impact and innovations across borders in a context of growing economic, social and environmental problems that are not being effectively addressed by the market and the State (Lindenberg 1999; André \& Pache 2016; Bretos, Díaz-Foncea \& Marcuello 2020).

Indeed, some studies suggest that international expansion of SEOs is far from a marginal phenomenon. For example, in a recent study on 300 of the largest co-ops and mutuals in the world, Bretos, Díaz-Foncea \& Marcuello (2018) found that the vast majority of them operate across borders through different strategies ranging from contractual typologies such as direct exports, franchising and licensing, to equity typologies such as greenfield investments, joint ventures and full acquisitions. These strategies are not confined to just a few large enterprises though. Smaller SEOs and social ventures are equally producing and offering their goods and/or services on a global scale. Information and communication technologies (ICTs) are critical for these organizations to achieve a global dimension and scale social impact across borders: ICTs allow SEOs to identify and exploit global social entrepreneurship opportunities, access to a wider range of funding sources (e.g., crowdfunding), and create social networks and entrepreneurial alliances to drive international growth (Zahra et al. 2008; Torres-Coronas \& Vidal-Blasco 2013). Not surprisingly, many of the new international SEOs and social ventures are born global from their inception (Marshall 2011).

This scenario raises some important questions for a better understanding of the nature and evolution of the New Social Economy. What strategies do SEOs deploy to expand their 
operations across borders and how scaling social impact is related to each strategy? What are the challenges for international SEOs in preserving and extending their socially oriented practices and values? What approaches can international SEOs adopt to maintain a sustainable balance between social and economic performance? Do they embody a genuine alternative in the international business arena to corporate managerialism and conventional multinationals? The chapter aims to shed some light on these questions. Being aware of the important national differences that exist in the world regarding the concept of social economy and the specific organizations that are part of this sector, in this chapter we adopt a broad and inclusive international approach that conceptualizes SEOs as organizations which, regardless of their legal form, engage in commercial activities to sustain their operations while pursuing a social mission and involving different stakeholders in decision making.

In the next section, we identify three major scaling strategies and provide some relevant examples of how high-profile SEOs are adopting these strategies. We also discuss the potential of these strategies to address different social and environmental issues on a global scale as well as to scale social impact and innovations across national boundaries. The third section discusses the main challenges faced by international SEOs not only to preserve their community orientation, cooperative practices and social values in the parent organization, but also to extend them across their international networks made up of branches, partners and/or implementers. The fourth section illustrates how SEOs can manage the challenges associated with international expansion. In particular, we draw on insights from five cutting-edge SEOs that are operating successfully on a global scale while engaging in social values and cooperative and communitarian practices. The last section is devoted to conclusions.

\section{Cross-border scaling strategies in SEOs}

Drawing on a review of the literature on social enterprise growth and scaling (e.g., Dees et al. 2004; Lyon \& Fernandez 2012; Nazarkina 2012; Heinecke \& Mayer 2012; Vickers \& Lyon 2014; André \& Pache 2016; Bauwens et al. 2019), we distinguish three major typologies of cross-border scaling strategies: control-based, altruism-based, and hybrid. As illustrated in Figure 1, these strategies can be placed along a continuum in terms of increasing degree of central control and resource requirements.

\subsection{Control-based international scaling strategies}

Control-based international scaling strategies rely on a considerable degree of centralized control and coordination, and generally require the greatest investment of resources by the parent organization (Dees et al. 2004). These strategies, which basically include cross-border mergers, acquisitions, and greenfield investments, involve the parent organization creating branch structures beyond its national borders in the form of company owned stores, offices, or plants (Heinecke \& Mayer 2012), that is, all units legally belong to of the parent organization. Control-based strategies are often pursued by SEOs seeking to increase the scale of operations, to acquire new capabilities and access resources while entering new geographic markets (Nazarkina 2012), many times as a way to preserve or stimulate their competitive position in highly globalized and dynamic markets (Bretos \& Marcuello 2017). 
Figure 1. Three major typologies of international scaling strategies

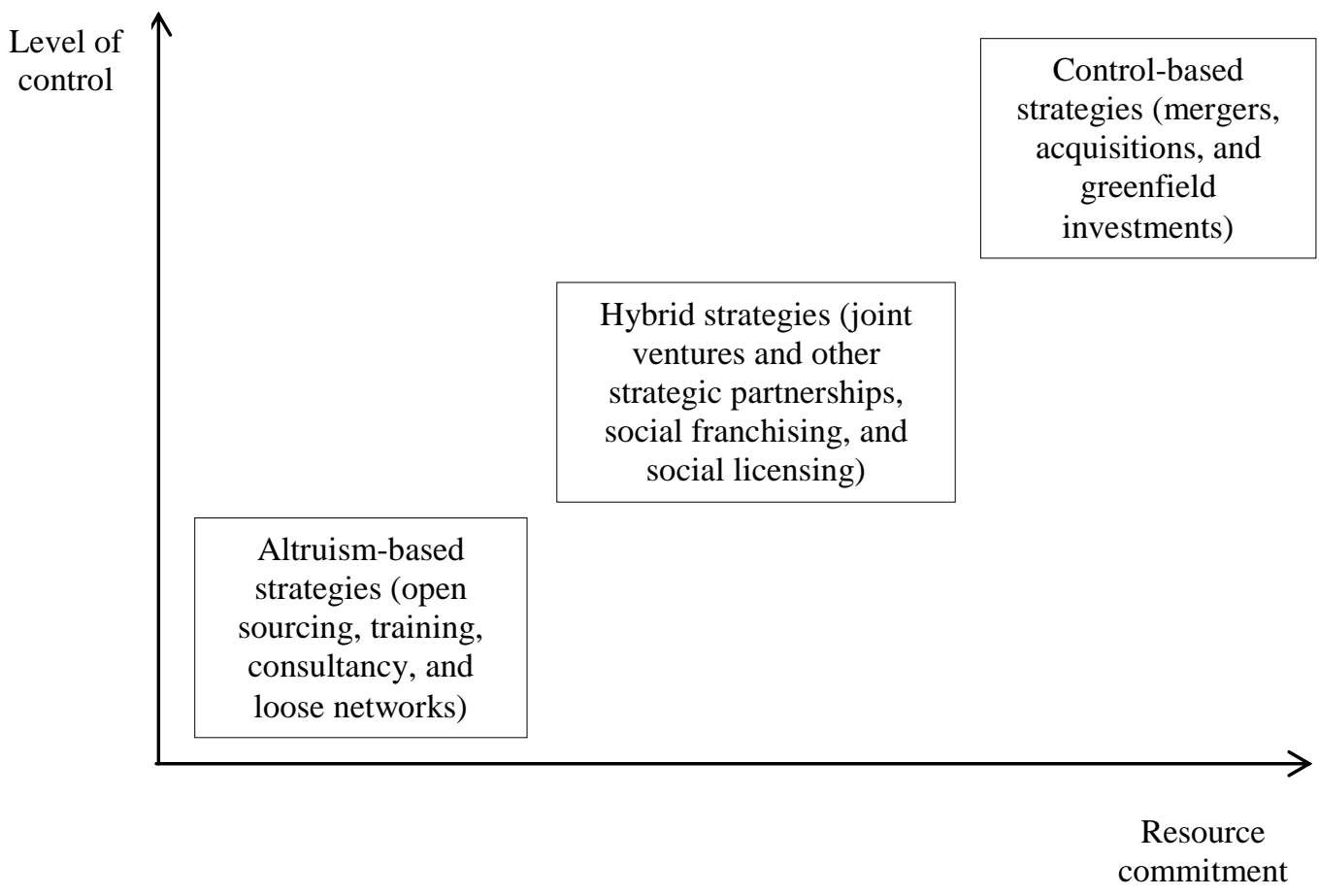

Source: own elaboration

Many of the organizations included in the World Co-operative Monitor's list of the 300 largest cooperatives and mutuals in the world embody relevant examples ${ }^{1}$ (Bretos, DíazFoncea \& Marcuello 2018). For instance, some industrial cooperatives from the Basque Country have pursued extensive acquisitive growth in international markets since the mid1990s in order to maintain their competitiveness and safeguard the jobs of the workermembers at the parent Basque plants (Bretos et al. 2019). These multinational co-ops tend to centralize major strategic, technical, financial and commercial decisions in the parent cooperative (Errasti et al. 2016). They combine the exercise of direct control by enforcing policies and practices in the subsidiaries with indirect control mechanisms based on monitoring by way of expatriate personnel and communication between headquarters and key managers in foreign plants (Bretos, Errasti \& Marcuello 2018). Internationalization strategies with similar degrees of central control have been equally adopted by SEOs in other sectors such as banking industry (e.g., Crédit Agricole, Raiffeisen Banking Group, Crédit Mutuel, and Rabobank) and agri-food industry (e.g., Danish Crown, Fonterra, Arla Foods, and FrieslandCampina) (Birchall, 2014; Bretos, Díaz-Foncea \& Marcuello 2018).

Other prominent examples beyond cooperatives and mutuals include large international non-profit organizations such as the well-known cases of BRAC and Ashoka. Bangladeshbased BRAC, which is the largest non-governmental development organization in the world, provides microloans, self-employment opportunities, health services, education, and legal and human rights services. With branches and operations in 14 countries, BRAC International was

\footnotetext{
${ }^{1}$ The World Co-operative Monitor is published annually since 2011 by the International Cooperative Alliance and the Institute Euricse, and can be downloaded from https://www.monitor.coop/en.
} 
set up in 2009 to govern and manage all BRAC entities outside Bangladesh, UK and USA (Hossain \& Sengupta 2009). Ashoka, meanwhile, is a non-profit organization dedicated to identifying and supporting outstanding social entrepreneurs worldwide, providing them with living stipends, professional support, and access to a global network of peers in more than 60 countries. The international board centralizes decision-making on the selection of social entrepreneurs to ensure consistency and the accomplishment of quality standards across all Ashoka subsidiaries (Heinecke \& Mayer 2012).

The other two strategies - altruist and hybrid - are more likely to be deployed by international social ventures of a more entrepreneurial nature, which identify and exploit opportunities across national borders to create new businesses, models, and solutions for value creation, including financial, social, and environmental (Zahra et al. 2014). In these expansion strategies, the primary goal of the organization is to increase social value creation.

\subsection{Altruism-based international scaling strategies}

Altruist strategies involve a disseminating organization that makes its social innovation internationally available by actively sharing information and/or providing technical assistance to one or more recipient organizations that seek to replicate the approach or model (Sezgi \& Mair 2010; Heinecke \& Mayer 2012). Also referred to as dissemination, scaling across, diffusion or spread, altruist strategies rely on few resources, and there is little or no centralized control by the source organization over the replication of the social innovation by the adopter (Dees et al. 2004), which tends to use the shared information and knowledge as it deems appropriate. Hence, the source organization is not interested in owning and appropriating the value created using its approach but in altruistically spreading its model, ideas or tools to generate broader social impact, that is, the focus of these strategies 'is on replication, diffusion by other actors, and adoption rather than organizational control' (Bauwens et al. 2019, p. 5). Common mechanisms for the diffusion of knowledge and information in altruist strategies include open sourcing, training, consultancy, and loose networks (Uvin et al. 2000; Lyon \& Fernandez 2012; Berelowitz et al. 2015).

Open sourcing involves an organization that creates and shares resources, materials and publications (e.g., brochures, best practice booklets, manuals, and online videos) guiding and advising others on how to implement the social innovation. In the case of training, the disseminating organization provides formal training to others, generally through courses, workshops or seminars, in order to teach how to replicate the social innovation. Consultancy, meanwhile, usually involves providing long-term expert advice on specific aspects/issues of the replication of the social venture or innovation in definite contexts (Berelowitz et al. 2015). KaBOOM! illustrates how SEOs can combine these different mechanisms. This US-based non-profit organization is dedicated to giving all kids - mainly in low-income communitiessafe and accessible play opportunities. In 2004 KaBOOM! started offering different free or low-cost resources in order to disseminate its model more widely. These included toolkits, training seminars, and technical assistance. The non-profit organization also made accessible for free the project's handbooks, as well as different publications, guidelines and best practices on its website (Dees et al. 2004; McLeod \& Fulton 2010). This dissemination strategy has enabled the construction of 3,100 playgrounds and rehabilitation of 17,000 play 
spaces both in the US and abroad ${ }^{2}$. Similarly, many SEOs encourage creation of spin-offs by providing training and technical support to the implementers. Indian non-profit organization Urmul, which is engaged in different areas of action including health, basic education, rural craft and weaving, and savings and credit, actively promotes creation of spin-offs through training and support of former staff (Uvin et al. 2000).

Lastly, in loose networks different individuals or organizations that pursue the same social mission form a network, but with little coordination or control. The originator shares resources with the network, which are used by the implementers under no formal agreement or contract to adopt the social innovation and adapt it to their local context (Berelowitz et al. 2015). Food Assembly can be considered an example of expansion through the use of loose networks. This organization operates an online platform enabling a direct trade between communities and local farmers and producers. Anyone can set up their own local branch. Food Assembly operates as a central body which provides the technological platform and support, as well as guidance and assistance to implementers, but with no formal contract or agreement (Berelowitz et al. 2015). Indeed, the central association is small and reports no shared results. Originated in France, today, the Food Assembly model is spread across Europe in different countries such as Spain, Italy, Belgium, and Germany ${ }^{3}$.

Another relevant case is REScoop.eu, a European network of renewable energy cooperatives (Rescoops). This network was informally established in 2011 in Belgium when the founders of six met to explore ways of promoting the Rescoop model across Europe (Huybrechts \& Haugh 2018). Today the network comprises 1,500 Rescoops owned by about 1 million citizens from a wide variety of European countries. Rescoop.eu basically coordinates the collaboration between members in different thematic working groups, aiming to provide their members direct access to experts and to build a forum for exchange. More specifically, the aims of the federation are (1) to represent the voice of citizens and renewable energy cooperatives to European policy makers; (2) to support the start-up of new Rescoops by providing them with useful tools and contacts; (3) to provide services for the European Rescoops; and (4) to promote the Rescoop business model throughout Europe ${ }^{4}$.

\subsection{Hybrid international scaling strategies}

Hybrid international scaling strategies offer the broadest range of possibilities for SEOs to expand across borders and scale social impact (Dees et al. 2004). They rely on long-term contractual organizational arrangements in which both the parent organization and the partners maintain their autonomy (Nazarkina 2012), although they usually imply a commitment of both parties to share information and pool some level of resources (Smith \& Stevens 2010). In hybrid strategies, the relationship between the parent organization and the partners can range from loose cooperation to strongly linked structures (Heinecke \& Mayer 2012). Hybrid strategies represent an intermediate solution in terms of resource commitment and control. In comparison to altruist strategies, hybrid modes allow the source organization to gain greater control over its adopters and the process of transfer of knowledge and

\footnotetext{
${ }^{2}$ https://kaboom.org/playgrounds

${ }^{3}$ https://laruchequiditoui.fr/fr

${ }^{4}$ https://www.rescoop.eu/federation
} 
information (Uvin et al. 2000). However, hybrid strategies also require more resources and support from the source organization. In addition, hybrid strategies are also capable of achieving more varied impact increments, as they can scale social impact both directly, by reaching a larger number of users, and indirectly, in a process through which the partners of the alliance or network can induce each other to carry out new activities and processes aimed at increasing social value creation (Sezgi \& Mair 2010). Hybrid strategies can originate either from a single organization that builds or becomes a parent organization to allow for further scaling up or replication (e.g. Berelowitz et al. 2015; Chen 2012; Guidici et al. 2018), or from different ventures or institutions teaming up in order to create, scale up and/or diffuse a common social innovation or model (e.g. Davies \& Doherty 2019; Jiwa 2007; Rattalino 2018). Common hybrid forms of scaling include social franchising, social licensing, joint ventures and other strategic partnerships.

International social franchising is basically the application of a commercial franchising approach on an international scale to achieve greater social impact, rather than profit (Tracey \& Jarvis 2007). This involves an organization systematizing and packaging its proven model or social innovation in a way that enables others to replicate it under a franchise agreement. A prominent example is Impact Hub, the largest global network of business incubators and coworking spaces for social businesses. Launched in London in 2005, this project quickly expanded in the early years through an innovative social franchising strategy that put the social mission at the very heart of expansion (Giudici et al. 2018). Today, the Impact Hub network comprises over 100 hubs with 16,500 members, located across 55 countries. Each hub is set up by local entrepreneurs who enjoy substantial autonomy to adapt the concept and model to their local contexts, while an Impact Hub global team provides them with knowhow, solutions and procedures (Impact Hub 2019). Another example is VisionSpring, a social enterprise whose mission is to ensure affordable access to eyewear for disadvantaged individuals and which embodies an alternative social micro-franchising system. Relying on the essence of the microcredit model, VisionSpring loans franchisees the necessary materials and resources to launch the business, and the latter repays only once they have activity and sales (Chen 2012).

International social licensing involves turning an innovation with social impact into intellectual property that can be licensed for use by others across borders. One example is the case of Green Gyms, run by the UK charity The Community Volunteering (TCV). These are outdoor sessions aimed at imparting a health and fitness focus to conservation projects. This model has been replicated in other countries such as Australia under the same trademark and the exclusive license from TCV, whose use requires the implementer (licensee) to pay an initial one-off fee. The license package includes training, evaluation, manuals for operations and management, and consultancy to start the Green Gym according to a set of quality standards (Berelowitz et al. 2015).

An international joint venture is an alliance formed by two or more independent entities based in different countries that aims to achieve common objectives. This implies the creation of a new entity, business activity or project (the joint venture) in which profits, losses, and control is shared by the partners. Many SEOs form joint ventures and partnerships among them to scale their social impact. For example, Cafédirect, a well-known British farmerowned, fair-trade social enterprise, was founded as a joint venture of four UK organizations 
involved in poverty alleviation: Oxfam, Traidcraft, Equal Exchange, and Twin Trading (Davies \& Doherty 2019). What is more, much of the subsequent national and foreign expansion pursued by Cafédirect has been achieved through partnerships with other organizations (Davies et al. 2010). Another example is Divine Chocolate, which operates in the UK and the US. This company is owned by Kuapa Kokoo, a Ghanaian cocoa farmers' cooperative; Twin Trading, a UK-based NGO working on market access for small-holder farmers; and the Dutch development finance cooperative Oikocredit ${ }^{5}$.

International public-private partnerships between organizations from the public and the not-for-profit sectors are also commonly used to address social concerns and unresolved needs more effectively, as well as to increase efficiency and quality in the provision of public services (Quelin et al. 2017). For instance, the German federally owned international cooperation enterprise GTZ and the British social enterprise Cafédirect set up AdapCC, a public-private partnership that operated between 2007 and 2010 in Kenya, Mexico, Nicaragua and Peru, and whose aim was to support small coffee and tea producers in their developing strategies to cope with the risks and impacts of climate change. Another relevant example is Honey Care, a Kenyan social enterprise that strives to raise incomes for rural farmers through apiculture. This organization has been particularly successful in raising funds via international aid grants and loans to scale social impact. In partnership with local NGOs, national governments, and international development and financial institutions, Honey Care has extended its venture to countries such as Tanzania and Malawi (Jiwa 2007).

Lastly, social purpose partnerships between not-for-profit organizations and large multinational corporations have also attracted notable interest in the last two decades (Shumate et al. 2018). These partnerships undertake commercial activities that allow for economic sustainability while implementing a social mission either through its processes or through the provided good/service. A good example is the Common Threads Initiative, which was launched through a partnership between the clothing B corporation Patagonia and the multinational e-commerce company eBay. This initiative aims to make, buy and use clothes more sustainably, specifically by reducing, repairing, reusing, and recycling the apparel that customers buy (Rattalino 2018).

\section{Challenges for international SEOs in preserving and extending socially oriented practices and values in international SEOs}

International growth and scaling imply great challenges for international SEOs to maintain a sustainable balance between social and financial performance (McMurtry \& Reed 2009). This involves not only preserving their community embeddedness and socially oriented practices and values, but also extending these across their international networks made up of branches, partners and/or implementers (Flecha \& Ngai 2014). When operating on an international scale, SEOs have to pursue the societal needs of a broader range of local communities and mutual benefits of the diverse stakeholders affected by their activities. At the same time, some SEOs must meet the increased efficiency and financial performance requirements associated with competing in highly globalized markets, while others are urged to implement their social innovations in culturally and institutionally distant contexts (Bretos \& Marcuello 2017).

\footnotetext{
${ }^{5}$ https://www.twin.org.uk/projects-partnerships/divine/
} 
Achieving such balance is extremely complex. Indeed, many SEOs have been found to be exposed to degenerative pressures whereby they depart from their original cooperative practices, communitarian purposes and/or social values to focus on market orientation (Smith et al. 2013). Degeneration mechanisms include premium on technocratic managerial expertise at the expense of rank-and-file participation; prioritization of profit-seeking goals; prevalence of a managerialist rhetoric that privilege concepts such as quality, customer service, efficiency, growth, and competitiveness; and reshaping of cooperative culture and practices in line with managerial prerogatives and concerns (Heras-Saizarbitoria 2014; Bretos, Errasti \& Marcuello 2018).

Some SEOs have also experienced processes of demutualization or transformation into conventional investor-owned multinationals due to different problems such as those related to financial performance, access to capital, member engagement, and governance (Sousa \& Herman 2012). In some cases, demutualization occurs via a merger, takeover or buyout of a SEO by a multinational corporation looking for new niche markets and, many times, pursuing a 'clean-wash' strategy. Some well-known cases include purchases of cruelty-free beauty products company The Body Shop by L'Oreal, organic beverage company Honest Tea by Coca-Cola, natural body care products company Tom's of Maine by Colgate, and organic yogurt maker Stonyfield by Danone Group (Austin \& Leonard 2008).

In the case of SEOs pursuing organizational growth through control-based and hybrid scaling strategies demutualization can also take place through the conversion of equity into investment shares. A prominent example is Kerry Co-op, an Irish food company that demutualized in order to respond to market challenges and obtain capital required for future growth and development of the organization. In 1986 the co-op created a public limited company Kerry Group PLC and exchanged the bulk of its assets for a majority shareholding in Kerry Group (Juliá et al. 2012). Since then, Kerry has achieved extraordinary expansion, regularly issuing shares, until having 147 manufacturing plants in 32 countries and selling its products in over 140 countries. Today, Kerry Co-op is a minority shareholder of Kerry Group, with only a $13.6 \%$ share in the PLC ${ }^{6}$. In extreme instances, international growth and global competition can result in the dissolution of a SEO (Sousa \& Herman 2012). This is the case of the Basque household appliances manufacturer co-op Fagor Electrodomesticos, which went bankrupt in 2013. Fagor Electrodomesticos, a weak and small company in comparison to its competitors and with a large part of its production activity located in high-cost countries, pursued a risky strategy of international growth that reached its peak with the takeover of the French giant Brandt for $€ 165$ million in 2005 . Fagor Electrodomesticos finally collapsed due to the severe economic downturn of 2008, after steadily accumulating debt and experiencing a drastic fall in sales (Errasti et al. 2016).

We now turn to discuss some challenges that are more specifically associated to each of the cross-border scaling strategies discussed in the previous section.

\subsection{Challenges associated to control-based strategies}

Organizational growth associated to control-based strategies can challenge the participatory governance practices that characterize many SEOs. As the organization grows in size,

\footnotetext{
${ }^{6}$ https://www.kerrygroup.com/annual-report/
} 
members might find more difficult to perceive a direct and tangible effect of their participation in decision making. Likewise, the cultural, geographical, or motivational heterogeneity of large memberships may result in the interests of some groups of members not being addressed. Overall, these factors may lead to a decline in members' involvement in the organization and delegation of decision making power in management (Bretos \& Errasti 2017; Errasti et al. 2017; Nilsson 2018). Other mechanisms are equally relevant. As the organization grows it becomes more difficult to establish an efficient flow of information between rank-and-file members and management, and organizational social capital can decline because trust and personal relationships are harder to foster (Nilsson et al. 2012).

Employee centered practices can also be endangered due to organizational growth. This is evident, for example, in the case of Digital Divide Data, a global social enterprise that provides disadvantaged people with economic opportunities through training and employment in an information technology outsourcing business. The company initially supported employees' training through grants. However, as the number of employees increased, the company had to look for alternatives to finance training, such as replacing outright grants to employees with loans (Smith et al. 2013). Likewise, growth can translate into the weakening of the embeddedness in the local community. In this regard, trust and social networks built through local ties with community actors become harder to preserve as the organization increases in size (Smith \& Stevens 2010). This has been evident, for example, in microfinance social enterprises that have significantly scaled operations under a more commercial approach while losing some communitarian social capital, as is the case of Grameen (Bateman 2010).

Many international SEOs deploying control-based strategies to expand across borders have been also criticized for not being willing to replicate their hallmark socially oriented practices and values in their branches. This is the case, for example, of non-profit groups owning forprofit offshoots to generate revenue and strengthen their competitiveness and market position (Smith 2010; Skelcher \& Smith 2015), or multinational co-operatives that have turned into 'coopitalist' hybrids formed by a parent co-operative and a capitalist periphery of noncooperative subsidiaries abroad (Bretos \& Errasti 2018). In the later, reasons behind the nontransfer of the co-operative model to overseas subsidiaries include institutional barriers such as absence of a legislation covering co-operatives and potential lack of a collectivistic culture and cooperative tradition in the recipient region. However, this might be more critically influenced by headquarters-subsidiary power relations, as well as by core co-op ownermembers looking to protect their own interests (Bretos et al. 2018). In this regard, parent coop owners tend to perceive the 'cooperativization' of foreign subsidiaries as detrimental for their own control over the business group and risky for the viability of the co-op because the subsidiary might take decisions that go against the former's interests (Bretos et al. 2019).

\subsection{Challenges associated with altruism-based strategies}

A key challenge associated with altruism-based scaling models lies in the fact that the source organization lacks control mechanisms regarding who replicates the approach or social innovation, for which purpose it is implemented, and whether its quality and essence is preserved (Heinecke \& Mayer 2012). This can result in the distortion of the approach and consequent damage to the brand image of the source organization, or of the social innovation 
in question, if the approach/innovation is not adequately applied, that is, if the social mission or innovation is perverted by pursuing purely economic goals or other personal concerns that go against general interest or the interest of the target audience.

This is illustrated to some extent by the case of Hippocampus Learning Centres (HLC), an Indian social enterprise whose mission is to transform the lives of underserved children through high-quality education. This SEO experienced some problems related to the distortion of its original approach during its initial dissemination across India, because some educational programs were not being replicated with the expected quality and some centers were not financially sustainable. When this experience was replicated in Mexico in 2016, however, HLC partnered with Connovo, a local social business specializing in the replication of social ventures to scale impact. With notable adaptation of the approach to the Mexican local context, for example, regarding the way in which the project was funded, the replication was highly successful (Conway \& Dávila 2018), and Hippocampus is now targeting to operate 100 centers by 2021 in this country ${ }^{7}$.

Alternatively, the initial lack of control stemming from the altruism-based replication strategy might lead some SEOs to consolidate autocratic monitoring models that stifle the adaptation of the approach/innovation to the local context in which it is being replicated, thereby seriously damaging ties between the initiative and local community. The Freecycle Network exemplifies this transition. Founded in the US in 2003 to promote a gift economy by connecting people to exchange free items for reuse or recycling in their local area, this initiative was quickly replicated in many countries, and hundreds of decentralized local groups were set up worldwide with substantial autonomy to implement the model. However, in 2009 most UK local groups broke away to set up the alternative network Freegle against accusations of increasing tight control from the US Freecycle parent and little room of maneuver for local adaptation, as well as growing concerns over the gradual erosion of Freecycle's grassroots ethos (Martin et al. 2015). Overall, this reveals how enforcing a model or approach in recipient communities according to the standards of the region of origin does not work, as well as how important it is for implementers to have autonomy to adapt the model/innovation to the local context, as they know its characteristics better. In addition, it illustrates how preserving the autonomy of the (replicated) local groups may be a way to counteract the erosion of social values and practices at the parent company and ensure the survival of a community orientation.

\subsection{Challenges associated with hybrid strategies}

Similar to the case of altruism-based scaling, purposeful distortion or misinterpretation of the original approach or social innovation can also emerge in hybrid scaling strategies such as franchising and licensing agreements, as the source organization does not have total control over the implementer (Heinecke \& Mayer 2012). Another potential problem is the lack of alignment between the interests of the source organization and the franchisee or licensee. These challenges were visible in the case of Aspire Group, a UK social enterprise that was founded in the late 1990s with the aim of providing employment for homeless people. This social enterprise experienced notable expansion through a social franchising strategy, but it

\footnotetext{
${ }^{7}$ https://hippocampus.in/about/snap-shot/
} 
failed due to different reasons including the lack of an efficient franchisee monitoring system and the fact that the goals of economic viability and social service provision were not successfully aligned in the franchising network (Nazarkina 2012). In the early stages of Aspire's expansion, the franchisees enjoyed notable autonomy in implementing the approach. As financial difficulties emerged, however, Aspire Group attempted to exercise greater centralized control over the franchisees and, moreover, its concerns shifted to financial survival, while the franchisees' priorities remained providing employment and support to homeless people (Tracey \& Jarvis 2007).

Tensions to maintain a sustainable balance between potentially contradictory goals are particularly prone to arise in cross-sector joint ventures and partnerships between corporations and SEOs (Di Domenico et al. 2009). This is due to the fact that profit-seeking and competitiveness concerns typical of corporations might clash with the social and/or environmental performance interests that characterize SEOs. A major problem for SEOs engaging in partnerships with mainstream corporations might lie in the adoption of businesslike practices and approaches at the expense of social mission due to the latter's influence, as well as in the lessening of organizational legitimacy from stakeholders (Huybrechts \& Nicholls 2013) such as beneficiaries and donors who might perceive partnering with conventional businesses as a 'pact with the devil' (Huybrechts et al. 2017).

The purchase of the American ice cream B corporation Ben \& Jerry's by the British-Dutch transnational consumer goods behemoth Unilever illustrates these challenges. While this was not a partnership but a takeover, this case is relevant because Ben \& Jerry's board retained total autonomy within Unilever to make decisions and pursue its own agenda, thus enjoying much more independence than any other of Unilever's subsidiaries. Despite this special status, the co-op has been criticized both internally by employees and externally by customers and social activists for drifting away from its original social and ecological roots while embracing, influenced by Unilever, market values and a more pronounced commercial orientation. For example, Ben \& Jerry's had to stop using their brand in political campaigns, such as anti-war demonstrations, because Unilever's ethical code required the company to remain apolitical (Haski-Leventhal et al. 2017).

\section{Innovations in international SEOs for balancing social and financial performance}

We now turn to discuss how international SEOs can manage the tensions, competing demands, and ethical dilemmas associated with international growth, both by preventing mission drift trends and by re-finding the expected equilibrium between financial and social performance. In this regard, we draw on insights from five cutting-edge SEOs operating in different industries and countries that have been particularly successful in engaging with social values and practices while generating financial value. The selected SEOs are Aravind, Mondragon Corporation, Up Group, Arla Foods, and Rabobank.

\subsection{Aravind Eye Care System}

Aravind Eye Care System is an Indian-based non-profit organization that provides eye care services to poor people. It is the world's largest provider of eye care, attending two million patients and performing 270.000 surgeries per year, most of them provided either free or 
steeply subsidized for the patient (Sezgi \& Mair 2010). Only in South India, Aravind's eye care facilities include 13 eye hospitals, 6 outpatient eye examination centres and 75 primary eye care facilities. Its manufacturing unit, Aurolab, produces two million lenses per year, which are exported to more than 120 countries.

Aravind has actively promoted the dissemination of its model beyond India. Its expansion illustrates how SEOs can deploy altruism-based strategies to scale social impact across borders and prevent distortions of the original approach by the implementer while, at the same time, avoiding exertion of the excessively centralized control that might hinder the replication and local adaptation of the approach beyond the national borders. Aravind's solution was the creation of the Lions Aravind Institute of Community Ophthalmology (LAICO) in 1992 in order to support eye care programs globally through consultancy and capacity building, management training and research. LAICO, which is Aravind Eye Care System's training and consulting arm, provides accompaniment and support for the replication of the model through a two-year consultancy process that includes assessment, capacity-building and strategic planning, implementation training, and monitoring (Berelowitz et al. 2015).

As noted by Sezgi \& Mair (2010), Aravind's diffusion model has been based on four mechanisms: (i) training of organizational members to teach them skills and instill values; (ii) rotation among organizational members to spread values in newly established hospitals; (iii) ensuring communication between hospitals both to monitor performance and to reinforce maintenance and spread of values; and (iv) providing updated templates containing their best practices to be shared with third party hospitals. Today, Aravind's approach has been replicated in more than 30 countries (Berelowitz et al. 2015).

\subsection{Mondragon Cooperative Corporation}

The Basque Country-headquartered Mondragon Cooperative Corporation (MCC) is the largest worker-owned-and-governed federation in the world. MCC employs near 81,000 workers across the world, most of them in 98 co-ops that control near 143 subsidiaries abroad. Operating in highly dynamic and globalized industries, many Mondragon co-ops have been compelled to pursue extensive growth both in the domestic and international markets since the early 1990s in order to maintain their competitive position vis-à-vis large multinational corporations and safeguard worker-members' jobs in the Basque plants (Bretos et al. 2019).

MCC illustrates how SEOs can reverse mission drift trends and re-find a more balanced equilibrium between social and financial performance. After decades of tremendous growth that distanced MCC from its original communitarian approach, cooperative practices and social values in favor of managerial prerogatives and market orientation, the group has been enveloped, since the mid-2000s, in a process of reflection directed at restoring essential aspects of the cooperative experience along three key areas: participation and cooperation, cooperative training and education, and social transformation.

Regarding participation and cooperation, many Mondragon multinational co-ops are boosting more democratic dynamics by opening up spaces for deliberation and more active participation of shop-floor workers, thus countervailing oligarchic trends that had been consolidated with international expansion and growth in the size of the co-ops. Some best practices include preparatory meetings held in small groups prior to the general assemblies in 
order to stimulate participation in those spaces; inclusion of members from all strata and hierarchical levels of the cooperative in the discussion and elaboration of the strategic plans; reconfiguration of mini-councils to strengthen information sharing; and creation of new spaces to broaden the workers' involvement, such as "social plant meetings" and "social business councils" in which information concerning management is shared, general cooperative matters are discussed, and social affairs are dealt with. Where cooperative training and education is concerned, MCC has introduced and renovated training courses for the co-operative members. Courses readdress philosophical, social, and practical aspects of the Mondragon cooperative movement, which had taken second stage for the benefit of the technical training in the last years. New courses also focus on social skills such as leadership and teamwork as well as management competencies in order to tackle a critical problem in many Mondragon multinational co-ops: many rank-and-file worker members lack strategic and business skills to decide on highly complex strategic issues associated with operating in highly globalized and competitive environments. The social transformation area, meanwhile, includes very diverse policies directed at reconnecting Mondragon co-ops with their commitment to community development. The actions in this field are very varied. Some relevant examples include the introduction by many industrial co-ops of environmental sustainability policies and circular economy practices, or the alliance between Mondragon and United Steelworkers, the largest industrial trade union in North America, to promote Mondragon-like industrial cooperatives across the US and Canada (Bretos et al. 2020).

\subsection{Up Group}

Up Group is the second largest co-op in France in terms of revenue and members. It is engaged in developing payment methods and management solutions that improve the vitality of companies and territories, as well as purchasing power and a better life for employees and citizens. Its services for employees include access to food, culture, recreation, education, home help and social assistance. Up Group serves 1.1 million clients (which include companies and public and social actors), while 26 million employees and citizens are beneficiaries of Up's services and products. This international co-operative group employs about 3,600 people across France and other 19 countries located in Western and Mediterranean Europe, Eurasia and the Americas ${ }^{8}$.

Up has grown significantly through non-cooperative subsidiaries both in France and abroad. However, Up's trade union tradition - the co-op was created by a score of French trade unionists in the 1960s and, today, all of the co-op's senior managers are required to be members of some trade union - has greatly influenced the company's strategy. Entry into some countries has been made by the hand of the trade union and co-operative movement. In other cases, decisions about whether and how to access new markets have been significantly shaped by Up's European Works Council and trade unions. For example, the Italian subsidiary was launched in partnership with the local co-operative movement, while in Spain the subsidiary was opened with notable help from Spanish trade unions (Poulnot \& Matray 2016). What is more, in the last years Up has attracted notable interest for designing and

\footnotetext{
${ }^{8}$ https://groupe.up.coop/en/who-are-we/up-an-independent-and-international-group
} 
implementing a strategy of re-mutualization through the cooperativization of capitalist branches. Denominated as "Roots and Wings", this long-term project aims to develop employee ownership across the subsidiaries, and thus strengthen the Group's co-operative model. This is part of a broader strategy in Up to revitalize its original democratic principles and to re-engage with the Social and Solidarity Economy movement after a period of extraordinary international expansion and business development.

Figure 2. Up's principles and commitments in introducing the co-operative model in the foreign subsidiaries

\begin{tabular}{|c|c|}
\hline Principles & Commitments \\
\hline Facilitate participatory governance & $\begin{array}{l}\text { - Regular information and sharing with employees on } \\
\text { the group's and the subsidiary's strategy, objectives } \\
\text { and results } \\
\text { - Encourage representation and engagement of } \\
\text { employees in the company, to foster social dialogue }\end{array}$ \\
\hline Fully embrace societal responsibility & $\begin{array}{l}\text { - Carry out actions for the greater good } \\
\text { - Maintain balanced relationship with partners }\end{array}$ \\
\hline Develop a cooperative management system & $\begin{array}{l}\text { - Mobilize and unite the staff so that they feel } \\
\text { empowered to get involved in the company. }\end{array}$ \\
\hline $\begin{array}{l}\text { Think of the company as a source of personal } \\
\text { fulfilment }\end{array}$ & $\begin{array}{l}\text { - Think of work as an enabling factor for individuals } \\
\text { to evolve } \\
\text { - Foster equality and diversity and encourage } \\
\text { collective living } \\
\text { - Ensure financial and social protection of employees } \\
\text { and their families }\end{array}$ \\
\hline $\begin{array}{l}\text { Create wealth to ensure our development and } \\
\text { share it in keeping with the values of the } \\
\text { Group }\end{array}$ & $\begin{array}{l}\text { - In keeping with the values of the Group, share the } \\
\text { wealth produced collectively } \\
\text { - Ensure the sustainability of the company }\end{array}$ \\
\hline
\end{tabular}

Source: Up Group (2018)

The first step in the Roots and Wings project was taken in 2016. Three French domestic subsidiaries were transformed into worker co-ops and their 250 workers were integrated as owner-members in Up. Thus, Up's co-operative membership base grew from 394 to 710 worker-member-owners (Up Group 2018). Where foreign subsidiaries are concerned, meanwhile, Up is pursuing a different strategy. Aware of the specific social, cultural, legal, financial, and governance features of each country where the subsidiaries are located, Up has designed a series of common, exportable principles and commitments to be applied by its foreign subsidiaries in order to bring them closer to the co-operative management model of the French parent company (see Figure 2).

\subsection{Arla Foods}

The co-op Arla Foods is the largest organic dairy producer in the world, employing 19,190 people all over the world. Born from the merger of Danish MD Foods and Swedish Arla, today, Arla Foods is owned by 10,319 dairy farmers from Denmark, Sweden, Germany, the UK, Belgium, Luxembourg and the Netherlands. Arla has significantly expanded until 
becoming a major global player in the food and beverages industry. It controls production plants in 12 countries, sales offices in 30 countries, and exports its products to 105 countries 9 . Arla is in fact one of the few European agri-food co-operatives whose membership base consists of farmers from different countries.

Arla stands out for designing and implementing the strategy "Good Growth" in 2015, as a route to shared value creation for the stakeholders and the company. This integral strategy combines the development of Arla as a global food company through business growth and expansion, with a strong commitment to social responsibility and environmental sustainability. More specifically, in the Good Growth strategy, three key pillars can be distinguished: responsible international growth, cooperative expansion, and the concern for environmental sustainability (Høvring 2017).

Responsible international growth includes a wide variety of commitments and actions concerning, for example, respect of human rights and international principles, workers' wellbeing and inclusion, and increased transparency and communication with stakeholders. Cooperative expansion involves, on the one hand, growth through cooperation. Arla's expansion largely relies on strategic alliances and partnerships. On the other hand, this strategy pursues the enlargement of cooperative membership and extension of democratic control. In this regard, farmers in acquired or newly created Arla's subsidiaries outside the country of origin have become owner-members of the co-op. What is more, the company is trying to move towards a 'One Global Arla', that is a company in which the co-operative business culture is shared by employees across all the subsidiaries (Arla Foods 2018). Environmental concerns in Arla's growth strategy include, among others, the commitment to reduce the company's carbon footprint, maintenance of animal welfare and biodiversity in the farms, and production and distribution of high quality, natural-source products. These elements of social responsibility and cooperative identity are reinforced in Arla not only through a powerful corporate discourse that emphasizes generation of shared value (Høvring 2017), but also by implementing social performance and environmental indicators to monitor advances and assess their impact.

\subsection{Rabobank}

Rabobank is an international financial services provider operating on the basis of co-operative principles. Its main activities include retail and wholesale banking, private banking, leasing and real estate services. In particular, it has specialized in financing activities for the agri-food sector. As a co-operative bank, Rabobank is owned by 101 local Rabobanks in the Netherlands which, in turn, belong to 1.9 million of client-member-owners. Rabobank Group employs nearly 42,000 people across forty countries worldwide and serves approximately 10 million customers ${ }^{10} \mathrm{~s}$.

The case of Rabobank reveals the importance of participatory governance in aligning prescriptions from distinct institutional logics to maintain a joint accountability to both social and economic goals, and thus preventing mission drift. In 2014 the co-op embarked in the

\footnotetext{
${ }^{9}$ https://www.arla.com/company/

${ }^{10}$ https://www.rabobank.com/en/about-rabobank/profile/index.html
} 
Great Governance Debate, a broad internal discussion about the revision of the governance structure and mechanisms to achieve a more decentralized organization. All local co-operative Rabobanks and Rabobank Nederland started operating as one co-operative bank. Among other issues, membership base also increased, and today more than $25 \%$ of Rabobank's clients are member-owners of a local bank. Meanwhile, local bank member councils became more specifically focused on the bank's local services and its role in the community. Their influence and control also extended to Rabobank as a whole, as each local Rabobank directly represents its members in the supreme management body of the co-op: The General Members Council (Rabobank 2019).

Figure 3. Main results of the governance revision in Rabobank

\begin{tabular}{|c|c|}
\hline Better cooperative & Better bank \\
\hline $\begin{array}{l}\text { Enhanced countervailing power of } \\
\text { members on Rabobank as a whole } \\
\text { - Increased transparency of roles and } \\
\text { responsibilities in organization } \\
\text { - Increased distinctiveness, enhanced } \\
\text { visibility, tangible participation in local } \\
\text { communities } \\
\text { - Streamlined decision-making process } \\
\text { and consultative structure }\end{array}$ & $\begin{array}{l}\text { - Full and prompt compliance with new regulatory, } \\
\text { supervisory and resolution requirements } \\
\text { - More efficient internal processes due to the } \\
\text { abolition of delegated supervision and more } \\
\text { effective monitoring of management performance } \\
\text { - Improved cost efficiency } \\
\text { - Annual accounts and income statement reflect } \\
\text { more strongly the financial solidity of Rabobank } \\
\text { Group }\end{array}$ \\
\hline
\end{tabular}

Source: Groeneveld (2016: 20)

Above all, this new configuration sought to turn Rabobank into a better co-op and a better bank, allowing a better alignment and monitoring of the relationship between social and trading activities (see Figure 3). Financial performance has been enhanced, for example, through the improved cost efficiency and introduction of more effective control strategies for monitoring management performance. At the same time, local Rabobanks operate now with a higher degree of independence so they can better align their activities with local communities' interests, member-owners' power in Rabobank's decision making has been enhanced, and a shared co-operative culture has been spread across employees in both the co-op and subsidiaries (Groeneveld 2016). Furthermore, the impact of social responsibility practices has also been more precisely evaluated. For example, in 2018 Rabobank assessed its contribution to the achievement of the Sustainable Development Goals, drawing results that show a substantial positive impact of its economic and social activities on 8 Goals (Rabobank 2019).

It is also worth noting that all the international SEOs analyzed have shown an extraordinary capacity to innovatively adapt their production processes, organizational structures, and services in order to respond to the ongoing Covid-19 crisis. For example, Up Group has signed an agreement with the global humanitarian organization Action Against Hunger to donate meal vouchers and hygiene kits to vulnerable people. Several Mondragon industrial cooperatives temporarily restructured their manufacturing processes to produce and supply face masks and ventilators to combat the Covid-19 disease in Spain, in a context of medical equipment shortage and national emergency. Among other measures, Aravind has 
disseminated through its website a series of videos and resources with information to prevent the spread of the virus. Rabobank has launched a specific loan program with advantageous conditions to support small and medium-sized enterprises and social entrepreneurs affected by the coronavirus downturn. Arla Foods is involved in several projects with public organizations to send out grocery packages to people at higher risk of severe illness. In sum, these cases illustrate how globally oriented SEOs and social entrepreneurs are mobilizing a wide range of resources and designing diverse solutions to provide communities with greater resilience to weather Covid-19's dramatic consequences (Zahra, 2020).

\section{Conclusions}

Contrary to the conventional wisdom and mainstream theory depicting SEOs as small sized organizations that exclusively operate on a local scale and suffer from different barriers and limitations for their growth, recent studies show that international expansion has become a key trend in the evolution and diffusion of the social economy sector globally. As this chapter illustrates, SEOs can operate successfully across borders, playing a key role in addressing growing environmental and social issues that are global in nature, such as poverty, worsening of health and living conditions, social exclusion, impoverished labor conditions, biodiversity depletion, and climate change.

Two main drivers of SEOs international expansion can be distinguished. First, growing globalization and international competition in many sectors have pressured some SEOs to adopt internationalization strategies in order to maintain their competitive position and safeguard their contribution to social welfare. Second, the fact that global economic, social and environmental problems are not being effectively addressed by the public and private capitalist sectors has created a growing demand for SEOs to implement solutions and scale up their social impact across borders.

These different drivers and rationales are critical in determining the choice of the scaling strategy by the SEO. As we have seen, SEOs looking to stimulate their competitive position in highly globalized and dynamic markets tend to adopt control-based scaling strategies, as these offer greater opportunities to increase the scale of their operations, access new capabilities and resources, and appropriate the financial value generated by the organization as a whole. SEOs primarily looking to scale their social impact beyond national boundaries, meanwhile, tend to adopt altruism-based strategies because these are prone to enable a rapid diffusion and wide replication of social innovations and solutions across different sectors and countries. ICTs are particularly relevant for these SEOs to scale their social impact because they enable dissemination of the information and sharing of the resources, materials and best practices with other organizations or entrepreneurs interested in replicating the social innovation or model, as well as providing the necessary online training and technical support. Lastly, SEOs deploying hybrid strategies combine social welfare and market logics in their international expansion and seem to seek both scaling social impact and enhancing financial performance. Indeed, these SEOs usually expand across borders through cross-sectoral partnerships with public organizations and mainstream businesses, reflecting how these SEOs blend different demands. 
International scaling in SEOs is not exempt from tensions and risks, as they face unique challenges for balancing social welfare and commercial goals effectively. These organizations confront different problems in preserving and extending their socially oriented practices and values. SEOs deploying control-based scaling strategies are exposed to degenerative pressures that might lead these organizations to embrace purely profit seeking goals, market values and managerialism practices. This is due to the fact that these SEOs face increased economic requirements and pressures for greater efficiency and financial performance associated with operating on the international scale, often in highly globalized and competitive markets. In the case of SEOs utilizing altruism-based scaling strategies, the main challenge is that the external implementer might distort and pervert the nature and values of the former's original model or solution. SEOs expanding across borders through hybrid scaling strategies mainly risk departing from their original practices and values when engaging in partnerships with public and private sector organizations that pursue different, often competing, objectives.

Nonetheless, the different case studies presented in this chapter illustrate how international SEOs can mobilize resources and activate processes of organizational change not only to prevent mission drift, but also to counterbalance degenerative processes and thus recover the expected equilibrium between social welfare and financial logics. The main mechanisms include recovery of countervailing social discourses emphasizing democracy, social transformation, and community development; reinforcement of social accounting and participatory governance; updating and institutionalization of education and training in the organizational culture; support from the source organization concerning the correct replication of the solution or innovation by the third parties; and dissemination of the parent organization's original social practices and values among its overseas branches or subsidiaries. The adaptability to changing international conditions also seems to be a critical feature of SEOs. As we have seen, the international SEOs analyzed in this chapter have successfully adapted their structures, approaches and services in order to respond to the societal, public health and environmental issues generated by the ongoing Covid-19 crisis.

In conclusion, the evidence collected illustrates how international SEOs can sustain and promote over time the distinctive social values, cooperative practices and communitarian approaches that make them genuine alternatives to corporate managerialism not only in their local, national contexts, but also in the international business arena.

\section{References}

Amin, A., Cameron, A. \& Hudson, R. (2002). Placing the Social Economy. London: Routledge.

André, K. \& Pache, A.C., (2016). From caring entrepreneur to caring enterprise: addressing the ethical challenges of scaling up social enterprises. Journal of Business Ethics, 133, 659-675.

Arla Foods (2018). Annual Report 2017. Viby, Denmark: Arla.

Austin, J., \& Leonard, H. (2008). Can the virtuous mouse and the wealthy elephant live happily ever after? California Management Review, 51, 77-102.

Bateman, M. (2010). Why Doesn't Microfinance Work? London: Zed Books. 
Bauwens, T., Huybrechts, B., \& Dufays, F. (2019). Understanding the diverse scaling strategies of social enterprises as hybrid organizations: The case of renewable energy cooperatives. Organization \& Environment, in press, DOI:10.1177/1086026619837126.

Berelowitz, D., Chopra, P., Coussa, G., et al. (2015). Social Replication Toolkit. London: Spring Impact.

Birchall, J. (2014). The governance of large co-operative businesses. Manchester: Cooperatives UK.

Bretos, I., Díaz-Foncea, M., \& Marcuello, C. (2018). Cooperativas e internacionalización: Un análisis de las 300 mayores cooperativas del mundo. CIRIEC-España, Revista de Economía Pública, Social y Cooperativa, 92, 5-37.

Bretos, I., Díaz-Foncea, M., \& Marcuello, C. (2020). International expansion of social enterprises as a catalyst for scaling up social impact across borders. Sustainability, 12(8), 3262; doi: 10.3390/su12083262.

Bretos, I. \& Errasti, A. (2017). Challenges and Opportunities for the Regeneration of Multinational Worker Cooperatives: Lessons from the Mondragon Corporation - A Case Study of the Fagor Ederlan Group. Organization, 24(2), 154-173.

Bretos, I. \& Errasti, A. (2018). The challenges of managing across borders in worker cooperatives: Insights from the Mondragon cooperative group. Journal of Co-operative Organization and Management, 6(1), 34-42.

Bretos, I., Errasti, A. \& Marcuello, C. (2018). Ownership, Governance, and the Diffusion of HRM Practices in Multinational Worker Cooperatives: Case Study Evidence from the Mondragon Group. Human Resource Management Journal, 28(1), 76-91.

Bretos, I., Errasti, A. \& Marcuello, C. (2019). Multinational Expansion of Worker Cooperatives and their Employment Practices: Markets, Institutions, and Politics in Mondragon. ILR Review, 72(3), 580-605.

Bretos, I., Errasti, A., \& Marcuello, C. (2020). Is there life after degeneration? The organizational life cycle of cooperatives under a 'grow-or-die' dichotomy. Annals of Public and Cooperative Economics, 91(3), 435-458.

Bretos, I. \& Marcuello, C. (2017). Revisiting Globalization Challenges and Opportunities in the Development of Cooperatives. Annals of Public and Cooperative Economics, 88(1), 47-73.

Burke, B. (2010). Cooperatives for "fair globalization"? Indigenous people, cooperatives, and corporate social responsibility in the Brazilian Amazon. Latin American Perspectives, $37,30-52$.

Chen, S. (2012). Creating sustainable international social ventures. Thunderbird International Business Review, 54(1), 131-142.

Conway, M., \& Dávila-Castilla, J.A. (2018). Modelando el emprendimiento social en México. Ciudad de México: LID Editorial.

Davies, I. A., Doherty, B., \& Knox, S. (2010). The rise and stall of a fair trade pioneer: The story of Cafédirect. Journal of Business Ethics, 92, 127-147.

Davies, I. A., Haugh, H., \& Chambers, L. (2019). Barriers to Social Enterprise Growth Journal of Small Business Management, 57(4), 1616-1636.

Dees, J.G., Anderson, B.B., \& Wei-Skillern, J. (2004). Scaling social impact. Stanford Social Innovation Review, 1(4), 24-32. 
Di Domenico, M.L., Tracey, P., \& Haugh, H. (2009). The dialectic of social exchange: theorizing corporate-social enterprise collaboration. Organization Studies, 30, 887-907.

Errasti A., Bretos I., \& Etxezarreta E. (2016). What do Mondragon Coopitalist multinationals look like? The rise and fall of Fagor Electrodomésticos S. Coop. and its European subsidiaries. Annals of Public and Cooperative Economics, 87, 433-456.

Errasti A., Bretos I., \& Nunez A. (2017). The Viability of Cooperatives: The Fall of the Mondragon Cooperative Fagor. Review of Radical Political Economics, 49, 181-197.

Flecha, R., \& Ngai, P. (2014). The challenge for Mondragon: Searching for the co-operative values in times of internationalization. Organization, 21(5), 666-682.

Giudici, A., Combs, J. G., Cannatelli, B. L., \& Smith, B. R. (2018). Successful scaling in social franchising: The case of Impact Hub. Entrepreneurship Theory and Practice, in press, DOI: $10.1177 / 1042258718801593$.

Groeneveld, J.M. (2016). The Road towards One Cooperative Rabobank. Utrecht, Netherlands: Rabobank.

Haski-Leventhal, D., Roza, L., \& Meijs, L. (2017). Congruence in corporate social responsibility: Connecting the identity and behaviour of employers and employees. Journal of Business Ethics, 143, 35-51.

Heinecke, A., \& Mayer, J. (2012). Strategies for scaling in social entrepreneurship. In C. Volkmann, K. Tokarski, \& K. Ernst (Eds.), Social entrepreneurship and social business (pp. 191-209). Wiesbaden, Germany: Gabler Verlag.

Heras-Saizarbitoria, I. (2014). The Ties that Bind? Exploring the Basic principles of WorkerOwned Organizations in Practice. Organization, 21(5), 645-665.

Hossain, N., \& Sengupta, A. (2009). Thinking Big, Going Global: The Challenge of BRAC's Global Expansion. IDS Working Paper 339.

Høvring, C.M. (2017). Corporate social responsibility as shared value creation: toward a communicative approach. Corporate Communications, 22(2), 239-256.

Huybrechts, B., \& Nicholls, A. (2013). The role of legitimacy in social enterprise-corporate collaboration. Social Enterprise Journal, 9(2), 130-146.

Huybrechts, B., \& Haugh, H. (2018). The Roles of Networks in institutionalizing new hybrid organizational forms: Insights from the European Renewable Energy Cooperative Network. Organization Studies, 39(8), 1085-1108.

Huybrechts, B., Nicholls, A., \& Edinger, K. (2017). Sacred Alliance or Pact with the Devil? How and Why Social Enterprises Collaborate with Mainstream Businesses in the FairTrade Sector. Entrepreneurship \& Regional Development, 29 (7-8), 586-608.

Imbroscio, D. L., Williamson, T., \& Alperovitz, G. (2003). Local policy responses to globalization: Place-based ownership models of economic enterprise. Policy Studies Journal, 31(1), 31-52.

Impact Hub (2019). Impact Report. Available at www.bepartofthechange.impacthub.net/.

Jiwa, F. (2007). Honey Care Africa. In Fairbourne, J., Gibson, S.W., \& Dyer, W.G. (Eds), Microfranchising (pp. 149-163). Northampton, MA: Edward Elgar.

Julià, J. F., Melià, E., \& García, G. (2012). Strategies developed by leading EU agrifood cooperatives in their growth models. Service Business, 6(1), 27-46.

Lindenberg M. (1999). Declining state capacity, volunteerism and the globalizationof the notfor-profit sector. Nonprofit and Voluntary Sector Quarterly, 28(4):147-67. 
Lukkarinen, M. (2005). Community Development, Local Economic Development and the Social Economy. Community Development Journal, 40(4), 419-424.

Lyon, F., \& Fernandez, H. (2012). Strategies for scaling up social enterprise: Lessons from early years providers. Social Enterprise Journal, 8, 63-77.

McLeod, H., \& Fulton, K. (2010). Breaking new ground: Using the Internet to Scale. A case study of KaBOOM! Monitor Institute.

McMurtry, J., \& Reed, D. (2009). Co-operatives in a Global Economy: The Challenges of Co-operation across Borders. Newcastle: Cambridge Scholars Publishing.

Marshall, R.S. (2011). Conceptualizing the international for-profit social entrepreneur. Journal of Business Ethics, 98, 183-198.

Martin, C. J., Upham, P., \& Budd, L. (2015). Commercial orientation in grassroots social innovation: Insights from the sharing economy. Ecological Economics, 118, 240-251.

Nazarkina, L. (2012). How sustainable are the growth strategies of sustainability entrepreneurs? In G. Mennillo (Ed.), Balanced growth. Berlin: Springer.

Nilsson, J. (2018). Governance costs and the problems of large traditional cooperatives. Outlook on Agriculture, 47, 87-92.

Nilsson, J., Svendsen, G.L.H., \& Svendsen, G.T. (2012). Are large and complex agricultural cooperatives losing their social capital? Agribusiness, 28, 187-204.

Peredo, A. M., \& Chrisman, J. J. (2006). Toward a theory of community-based enterprise. Academy of Management Review, 31, 309-328.

Poulnot, J.L. \& Matray, M. (2016). Promoting social and solidarity economy: The Up Group Experience. 31st CIRIEC International Congress. Reims, France: CIRIEC International.

Quelin, B. V., I. Kivleniece and S. Lazzarini (2017). Public-private collaboration, hybridity and social value: towards new theoretical perspectives. Journal of Management Studies, 54(6), pp. 764-792.

Rabobank (2019). Annual Report 2018. Utrecht, Netherlands: Rabobank.

Rattalino, F. (2018). Circular advantage anyone? Sustainability-driven innovation and circularity at Patagonia, Inc. Thunderbird International Business Review, 60(5), 747-755.

Rothschild, J. \& Whitt, J. A. (1986). The cooperative workplace: Potentials and dilemmas of organisational democracy and participation. New York: Cambridge University Press.

Sezgi, F., \& Mair, J. (2010). To control or not control: a coordination perspective to scaling. In P. Bloom \& E. Skloot (Eds.), Scaling social impact: New thinking (pp. 29-44). New York: Palgrave Macmillan.

Shrisvastava, P., \& Kennelly, J. J. (2013). Sustainability and place-based enterprise. Organization \& Environment, 26, 83-101.

Shumate, M., Hsieh, Y. P., \& O’Connor, A. (2018). A nonprofit perspective on businessnonprofit partnerships: Extending the symbiotic sustainability model. Business \& Society, 57(7), 1337-1373.

Skelcher, C., \& Smith, S. R. (2015). Theorizing hybridity: Institutional logics, complex organizations, and actor identities: The case of nonprofits. Public Administration, 93(2), 433-448.

Smith, S. R. (2010). Hybridization and Nonprofit Organizations: The Governance Challenge. Policy and Society, 29(3), 219-29. 
Smith, B. R., \& Stevens, C. E. (2010). Different types of social entrepreneurship: The role of geography and embeddedness on the measurement and scaling of social value. Entrepreneurship \& Regional Development, 22(6), 575-598.

Smith, W. K., Gonin, M., \& Besharov, M. L. (2013). Managing social-business tensions: A review and research agenda for social enterprise. Business Ethics Quarterly, 23(3), 407442.

Sonnino, R., \& Griggs-Trevarthen, C. (2013). A resilient social economy? Insights from the community food sector in the UK. Entrepreneurship \& Regional Development, 25, 272 292.

Sousa, S. \& Herman, R. (Eds.) (2012). A Co-operative Dilemma: Converting Organizational Form. Saskatoon, Canada: Centre for the Study of Co-operatives.

Torres-Coronas, T., \& Vidal- Blasco, M. (2013). Social E-Enterprise: Value Creation trough ICT. Pennsylvania, US: IGI Global.

Tracey, P., \& Jarvis, O. (2007). Toward a theory of social venture franchising. Entrepreneurship Theory \& Practice, 31(5), 667- 685.

Up Group (2018). Annual Report 2017. Gennevilliers, France: Up Groupe.

Uvin, P., Pankaj, S., Jain, L., \& Brown, D. (2000). Think large and act small: toward a new paradigm for NGOs scaling up. World Development, 28(8), 1409-1419.

Vickers, I., \& Lyon, F. (2012). Beyond green niches? Growth strategies of environmentallymotivated social enterprises. International Small Business Journal, 32, 449-470.

Zahra, S. A. (2020). International entrepreneurship in the post Covid world. Journal of World Business, in press, doi: 10.1016/j.jwb.2020.101143.

Zahra, S. A., Rawhouser, H. N., Bhawe, N., Neubaum, D. O., \& Hayton, J. C. (2008). Globalization of social entrepreneurship opportunities. Strategic Entrepreneurship Journal, 2(2), 117-131.

Zahra, S., Newey, L. and Li, Y. (2014). On the frontiers: The implications of social entrepreneurship for international entrepreneurship. Entrepreneurship Theory and Practice, 38, 137-58. 